ORIGINAL PAPER

\title{
EXPRESSION OF RESISTIN IN THE LIVER OF PATIENTS WITH NON-ALCOHOLIC FATTY LIVER DISEASE
}

\author{
Piotr Gierej $^{1}$, Beata Gierej ${ }^{2}$, Piotr Kalinowski ${ }^{3}$, Tadeusz Wróblewski ${ }^{3}$, \\ Rafae Paluszkiewicz ${ }^{3}$, Konrad Kobryń ${ }^{3}$, Bogna Ziarkiewicz-Wróblewska ${ }^{2}$
}

\author{
${ }^{1}$ Department of Breast Cancer and Reconstructive Surgery, Maria Skłodowska-Curie Memorial Cancer Centre and In- \\ stitute of Oncology, Warsaw, Poland \\ ${ }^{2}$ Department of Pathology, Medical University of Warsaw, Warsaw, Poland \\ 3Department of General, Transplant and Liver Surgery, Medical University of Warsaw, Warsaw, Poland
}

\begin{abstract}
Adipokines are cytokines that presumably connect the pathologies of metabolic syndrome. One of the adipokines is resistin, the role of which in insulin resistance, obesity, and non-alcoholic fatty liver disease (NAFLD) needs to be determined. Liver biopsy specimens were obtained intraoperatively from 214 obese patients. Histological assessment was based on NAFLD activity score according to Kleiner. Statistical analysis involved semi-quantitive immunohistochemistry assessment of resistin staining and: NAFLD status in obese patients compared with a non-obese control group, selected clinical data (age, sex, body mass index - BMI), selected biochemical data, comorbidities (hypertension, type 2 diabetes mellitus, dyslipidaemia), and metformin treatment in patients with type 2 diabetes mellitus. Resistin expression was observed in the histiocytes of inflammatory infiltrate, Kupffer cells, and histiocytes surrounding the hepatocytes with steatosis. There was a positive correlation between the total expression of resistin and: (1) NAFLD advancement (NAFLD Activity Score- NAS), (2) AST, ALT, BMI, glucose, insulin, Homeostasis Model Assessment (HOMA), LDH, GGT, triglycerides (TG), and glycated haemoglobin $\left(\mathrm{HbA}_{1 \mathrm{c}}\right)$. Resistin expression was more intense in patients with type 2 diabetes mellitus and dyslipidaemia and less intense in the control group. Resistin probably plays a role in the pathogenesis of hepatic insulin resistance and aggravates pathologic changes in the liver of patients with NAFLD.
\end{abstract}

Key words: adipokines, insulin resistance, steatohepatitis, obesity.

\section{Introduction}

Non-alcoholic fatty liver disease (NAFLD) is defined as a lipid accumulation exceeding $5 \%$ of hepatocytes. It is estimated that NAFLD is present in $17-33 \%$ of the population in developed countries [1]. However, its prevalence among obese people may reach $70-80 \%$ [1]. NAFLD is related to increased mortality risk, with primary causes of death being advanced liver disease, cardiovascular disease, and diabetes mellitus [2]. Cytokines released from the adipose tissue called adipokines seem to be important contributing factors in the development of NAFLD (ranging from steatosis to cirrhosis). Adipokines are believed to constitute an important link between obesity, insulin resistance, and NAFLD. One of the adipokines is resistin. In animals, it is mainly released from adipose tissue, while in humans it is released from macrophages [3]. The exact role of resistin in the pathogenesis of NAFLD is ambiguous. Its correlation with liver insulin resistance, steatosis, liver inflammation, and obesity has been suggested [1, 3, 4]. 
Table I. Study group characteristics based on NAFLD activity score according to Kleiner [5]

\begin{tabular}{lcccc}
\hline NAS scale total score & 0 & $1-2$ & $3-4$ & $5-8$ \\
\hline No. of patients & $9(4.2 \%)$ & $27(12.6 \%)$ & $66(30.8 \%)$ & $112(52.4 \%)$ \\
\hline $\begin{array}{l}\text { Steatosis score in } \\
\text { NAS scale }\end{array}$ & 0 & 1 & 2 & 3 \\
\hline $\begin{array}{l}\text { No. of patients } \\
\text { Inflammation score }\end{array}$ & $37(17.3 \%)$ & $73(34.1 \%)$ & $79(36.9 \%)$ & $25(11.7 \%)$ \\
$\begin{array}{l}\text { in NAS scale } \\
\text { No. of patients }\end{array}$ & $14(6.5 \%)$ & 1 & 2 & 3 \\
\hline Liver cell injury (ballooning) score in NAS scale & $52(24.3 \%)$ & $89(41.6 \%)$ & $59(27.6 \%)$ \\
\hline No. of patients & 0 & $51(23.8 \%)$ & 1 & 2 \\
\hline Fibrosis stage & $123(57.5 \%)$ & $74(34.6 \%)$ & $14(6.5 \%)$ & $67(31.3 \%)$ \\
\hline No. of patients & & 1 & $3(1.4 \%)$ \\
\hline
\end{tabular}

The aims of the study included the following:

1. Immunohistochemical assessment of resistin expression in the liver of morbidly obese patients undergoing bariatric surgery.

2. Evaluation of the correlation between resistin expression and NAFLD advancement in obese patients in comparison with an obese non-NAFLD group and non-obese control group.

3. Assessment of resistin expression correlation with selected clinical and biochemical data, comorbidities, and metformin treatment in diabetic type 2 patients.

\section{Material and methods}

\section{Materials}

The study is a retrospective analysis. Liver biopsy specimens were obtained routinely via intraoperative incisional biopsy from 214 morbidly obese patients operated on at the Chair and Department of General, Transplant, and Liver Surgery, Medical University of Warsaw during the period from 2005 to 2013. The control group was made up of specimens taken from 17 patients with normal weight operated due to haemangiomas of the liver between 2002 and 2013. The specimens were embedded in paraffin blocks. They were evaluated by one experienced pathologist from the Chair and Department of Pathology of the University Hospital.

The patients were qualified for bariatric surgery if their BMI was $\geq 40 \mathrm{~kg} / \mathrm{m} 2$ or if their BMI was $\geq$ 35 with at least one comorbidity, such as hypertension, type 2 diabetes mellitus, or dyslipidaemia. The mean age of patients was 42.3 years (range 19-65) and mean BMI was 46.8 (range 33.5-71.6). Diabetes was diagnosed in $42.1 \%$, hypertension in $60.7 \%$ and dyslipidaemia in $42.9 \%$ of patients. Women accounted for $63.1 \%$ of the patients.

\section{Histology}

Liver specimens were fixed in $4 \%$ formalin, and standard haematoxylin and eosin (HE) staining was performed. The antigen retrieval was performed in PT Link (DAKO) in Targent Retrieval Solution highpH buffer (DAKO K8004). For immunohistochemical staining, primary anti-resistin monoclonal mouse antibody was used (Acris, AM01373PU-N, 1:500 dilution in Antibody Diluent - DAKO En Vision Flex K8006, visualization DAB). Immunohistochemistry was also performed with CD68 antibody (Flex Monoclonal Mouse Anti-Human CD68, Clone KP1, Ready-to-Use, DAKO GA609). To evaluate the fibrosis, Silver Impregnation for reticulum 04-040801 was used (Bio-Optica special stains kit).

Histological assessment was based on NAFLD activity score according to Kleiner [5]; non-alcoholic steatohepatitis (NASH) was recognised if the score exceeded four points. Histological group characteristics are shown in Table I.

The assessment of resistin expression was semi-quantitative in:

- the histiocytes (macrophages) of inflammatory infiltrate (0-3 pts),

- sinusoidal Kupffer cells (0-3 pts),

- histiocytes surrounding the hepatocytes with steatosis (0-3 pts).

The total expression of resistin was the sum of all points.

Expression was scored as the following: 0 - if there was no expression, 1 - if there was expression in $1-10 \%$ cells, 2 - if there was expression in $11-30 \%$ cells, 3 - if there was expression in $>30 \%$ cells.

\section{Statistical analysis}

Statistical analysis included the correlations/differences between: 
1. Immunohistochemistry results of resistin expression and NAFLD advancement (NAS scale, inflammation, steatosis, hepatocytes ballooning, and fibrosis) in obese patients compared with a nonobese control group.

2. Immunohistochemistry results of resistin expression and:

- selected clinical data (patient's age, sex, BMI),

- the levels of selected biochemical parameters (leucocytes, lymphocytes, monocytes, eosinophils, neutrophils, haemoglobin, MCV, platelet count, protein, albumin, $\mathrm{C}$-reactive protein [CRP], bilirubin, AST, ALT, de Ritis index [AST/ ALT ratio], LDH, ALD, GGT, total cholesterol [TC], HDL, LDL, TG, atherogenicity index (TC/HDL-C ratio), glucose, uric acid, creatinine, $\mathrm{HbA}_{1 \mathrm{c}}$, INR, fibrinogen, vitamin $\mathrm{B}_{12}$, C-peptide, insulin, Homeostasis Model Assessment [HOMA index $=$ fasting insulin $\{\mu \mathrm{IU} / \mathrm{ml}\} \times$ fasting glucose $\{\mathrm{mmol} / \mathrm{l}\} / 22.5]$, iron, Total Iron Binding Capacity [TIBC], transferrin, ferritin, folic acid),

- comorbidities of metabolic syndrome (hypertension, type 2 diabetes mellitus, dyslipidaemia),

- metformin treatment in patients with type 2 diabetes mellitus.

U Mann-Whitney test was used to compare the differences in total resistin expression between the study group and controls, while the chi-square test was employed to compare the differences in resistin distribution in macrophages, Kupffer cells, and histiocytes surrounding the hepatocytes with steatosis between the study group and the control group.

Chi-square test was used to investigate possible dependence of resistin expression in macrophages, Kupffer cells, and histiocytes surrounding the hepatocytes with steatosis upon the levels of the analysed binary variables (sex, dyslipidaemia, diabetes mellitus). U Mann-Whitney test was used to check if total resistin levels differed depending on the category of binary variables (sex, dyslipidaemia, diabetes). ANOVA (analysis of variance) was performed to determine whether mean levels of continuous variables depended on the level of resistin expression. The correlation between total resistin expression and continuous variables was also investigated by calculating the Spearman correlation coefficient. P values $<0.05$ were considered to be statistically significant.

\section{Results}

The assessment of resistin location in the liver showed:

1. Lack of resistin expression in hepatocytes.

2. In each case, resistin expression was noted in histiocytes of the infiltrate (Fig. 1).

3. Expression of resistin in the Kupffer cells (Fig. 2), correlated with NAS scale.

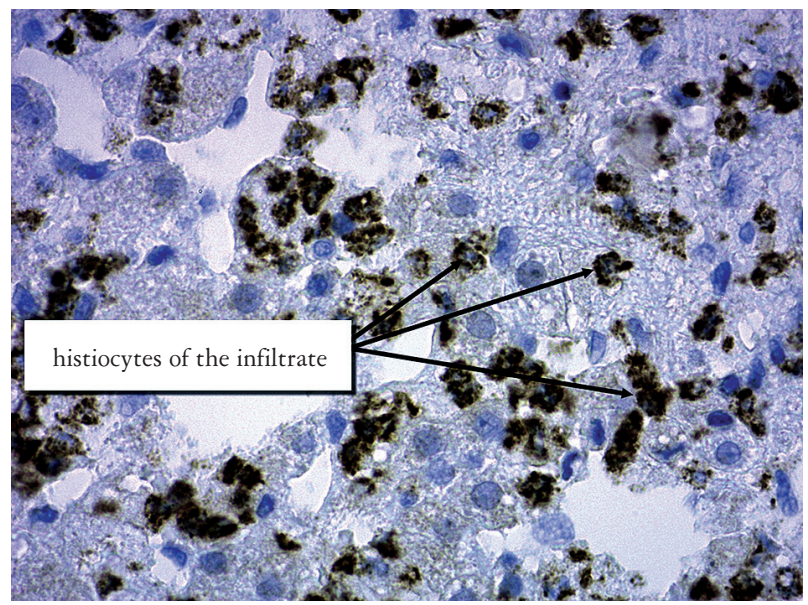

Fig. 1. Resistin expression in the histiocytes of inflammatory infiltrate (the objective lens magnification is $40 \times$ )

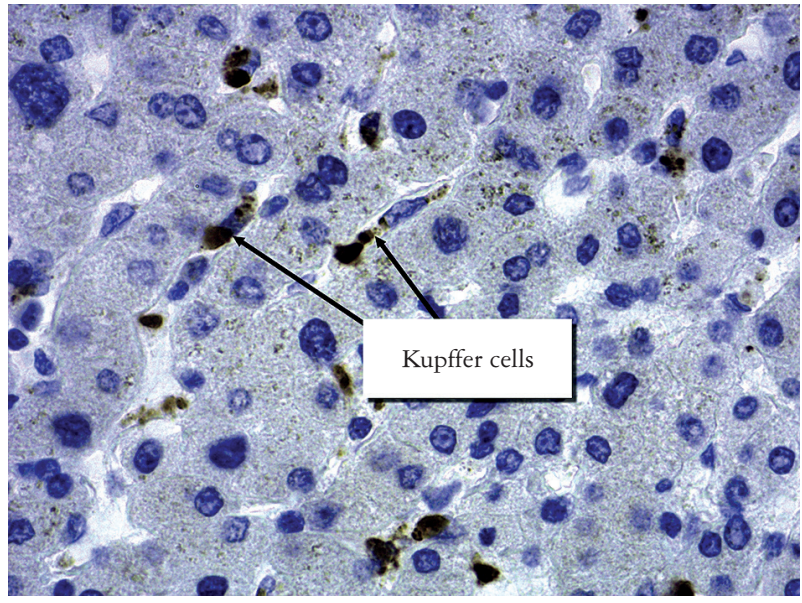

Fig. 2. Resistin expression in sinusoidal Kupffer cells (the objective lens magnification is $40 \times$ )

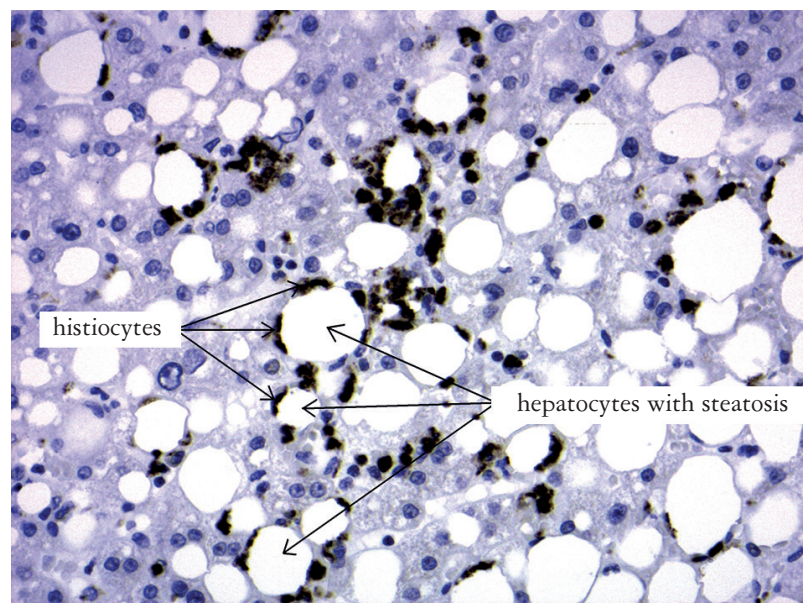

Fig. 3. Resistin expression in histiocytes surrounding the hepatocytes with steatosis (the objective lens magnification is $40 \times$ )

4. Resistin expression in histiocytes (CD68+) surrounding the steatotic hepatocytes (Fig. 3), correlated positively with NAFLD advancement.

There was a positive correlation of resistin expression with Kleiner NAFLD status in all basic param- 
Table II. Results for resistin expression according to location and NAFLD Activity Score scale parameters

\begin{tabular}{|c|c|c|c|c|c|}
\hline \multicolumn{2}{|c|}{ LOCATION OF RESISTIN EXPRESSION } & \multirow{2}{*}{$\begin{array}{c}\text { HisTIOCYTES } \\
\text { OF THE INFILTRATE } \\
0.502\end{array}$} & \multirow{2}{*}{$\begin{array}{c}\text { KuPFFER } \\
\text { CELLS } \\
0.164\end{array}$} & \multirow{2}{*}{$\begin{array}{c}\text { HISTIOCYTES SURROUNDING } \\
\text { THE STEATOTIC HEPATOCYTES } \\
0.562\end{array}$} & \multirow{2}{*}{$\begin{array}{c}\begin{array}{c}\text { TOTAL RESISTIN } \\
\text { EXPRESSION }\end{array} \\
0.478\end{array}$} \\
\hline NAS score & $\begin{array}{c}\text { Correlation } \\
\text { coefficient }\end{array}$ & & & & \\
\hline & $\mathrm{p}$ value & 0.000 & 0.019 & 0.000 & 0.000 \\
\hline \multirow[t]{2}{*}{ Steatosis score } & $\begin{array}{c}\text { Correlation } \\
\text { coefficient }\end{array}$ & 0.401 & 0.188 & 0.507 & 0.435 \\
\hline & $\mathrm{p}$ value & 0.000 & 0.006 & 0.000 & 0.000 \\
\hline \multirow[t]{2}{*}{$\begin{array}{l}\text { Inflammation } \\
\text { score }\end{array}$} & $\begin{array}{l}\text { Correlation } \\
\text { coefficient }\end{array}$ & 0.566 & 0.272 & 0.604 & 0.571 \\
\hline & $\mathrm{p}$ value & 0.000 & 0.000 & 0.000 & 0.000 \\
\hline \multirow{2}{*}{$\begin{array}{l}\text { Liver cell injury } \\
\text { (ballooning) } \\
\text { score }\end{array}$} & $\begin{array}{c}\text { Correlation } \\
\text { coefficient }\end{array}$ & 0.272 & 0.192 & 0.288 & 0.275 \\
\hline & $\mathrm{p}$ value & 0.000 & 0.005 & 0.000 & 0.000 \\
\hline
\end{tabular}
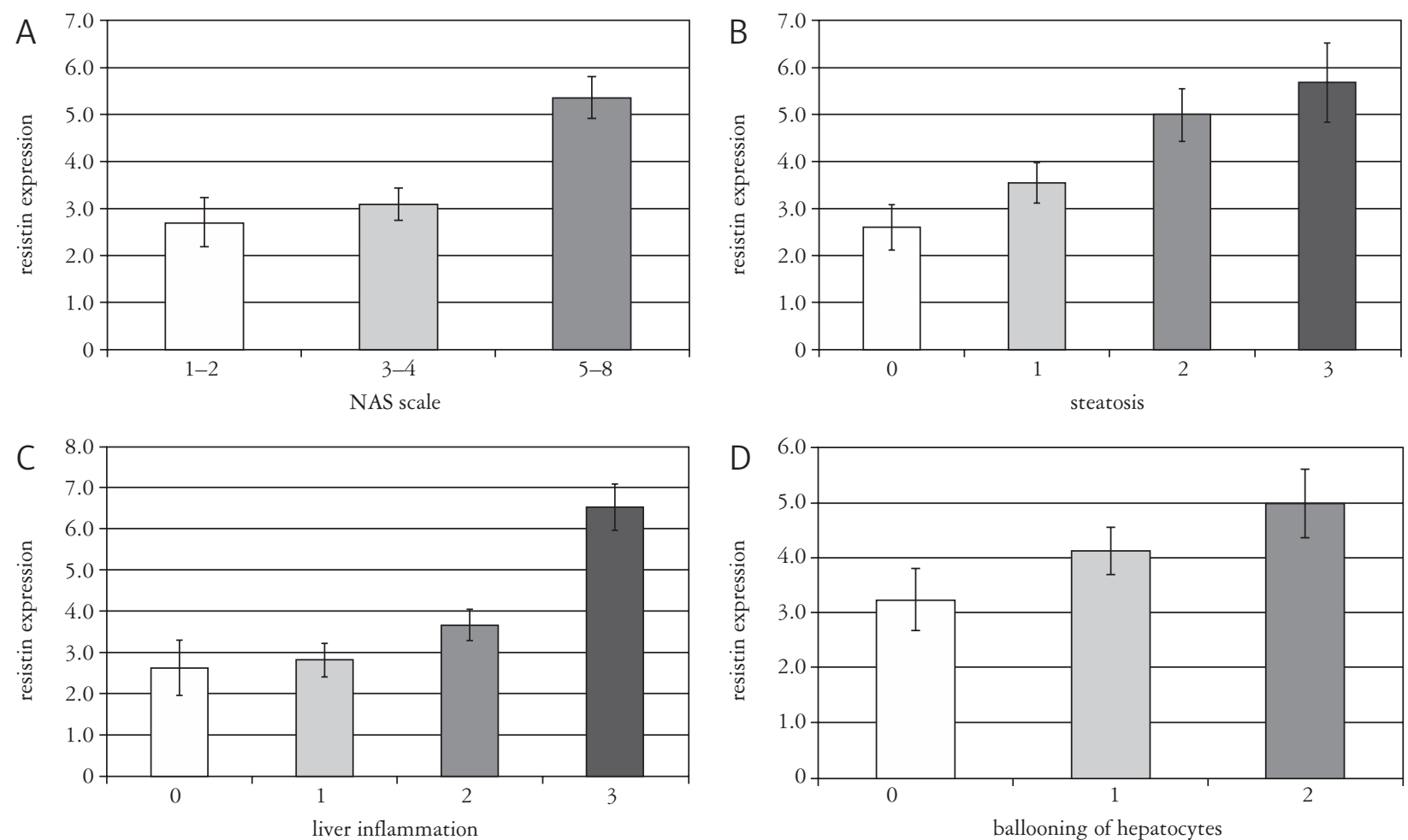

Fig. 4. Mean total resistin expression depending on: A) NAS scale, B) steatosis, C) liver inflammation, D) ballooning of hepatocytes

eters: total NAS score, the level of hepatocyte steatosis, the severity of inflammation, and ballooning of hepatocytes (Table II). This correlation was observed at all locations of analysed resistin expression: in the histiocytes of the inflammatory infiltrate, in the Kupffer cells, in histiocytes surrounding the hepatocytes with steatosis, as well as in total resistin expression. No such correlation was observed with the severity of organ fibrosis at either of the locations analysed, including the total assessment. Graphi- cal interpretation for the total resistin expression is shown in Fig. 4.

\section{Analysis of resistin expression in the histiocytes of inflammatory infiltrate}

There was a statistically significant correlation with the levels of glucose, $\mathrm{HbA}_{1 \mathrm{c}}$, insulin, triglycerides, HOMA index, and vitamin $\mathrm{B}_{12}$ (Table III). For other biochemical parameters, statistical significance was 
not reached (in the case of: AST: $\mathrm{p}=0.081$, ALT: $\mathrm{p}=0.074$, and C-peptide: $\mathrm{p}=0.082$ ). No differences were observed between the study group and the control group. No statistically significant correlation was found with patient's age and BMI. The difference in resistin expression was not noted with sex, hypertension, or metformin treatment. Also in the case of dyslipidaemia the difference was not statistically significant $(p=0.089)$.

\section{Analysis of resistin expression in Kupffer cells}

There was a statistically significant association with the levels of albumin, vitamin $B_{12}$, and $\mathrm{HDL}$ cholesterol (Table III). For other biochemical parameters, statistical significance was not reached (in the case of: de Ritis index $\mathrm{p}=0.057$, total protein $\mathrm{p}=0.064$, and $\mathrm{HbA}_{1 \mathrm{c}} \mathrm{p}=0.092$ ). No statistically significant correlation was observed with patient's age or BMI, and no difference in resistin expression was noted with sex, hypertension, metformin treatment, diabetes mellitus, or dyslipidaemia. A significant difference was demonstrated in resistin expression in Kupffer cells between the control group and the study group.

\section{Analysis of resistin expression in histiocytes} surrounding the hepatocytes with steatosis

There was a statistically significant positive correlation with the level of: AST, ALT, glucose, $\mathrm{HbA}_{1}$, insulin, triglycerides, and HOMA index (Table III). For other biochemical parameters, statistical significance was not reached (in the case of: AST/ALT $\mathrm{p}=0.095$ and TC/HDL $\mathrm{p}=0.089)$. No statistically significant correlation was observed with patient's age or BMI, and no difference was noted with sex, hypertension, or metformin treatment. In the case of diabetes mellitus and dyslipidaemia the difference in resistin expression was close to statistical significance (Table III). A significant difference was demonstrated in resistin expression between the control group and the study group.

Analysis of total resistin expression (sum of expression sites in macrophages of the inflammatory infiltration, in Kupffer cells and in histiocytes surrounding the hepatocytes with steatosis).

There was a statistically significant positive correlation with the levels of: triglycerides, glucose, $\mathrm{HbA}_{1 \mathrm{c}}$, insulin, AST, ALT, LDH, GGTP, and HOMA index (Table III). For other biochemical parameters,

Table III. Analysis of resistin expression with statistically significant parameters according to location

\begin{tabular}{|c|c|c|c|c|c|}
\hline \multirow[t]{3}{*}{ PARAmeter } & \multicolumn{5}{|c|}{ LOCATION } \\
\hline & \multirow{2}{*}{$\begin{array}{c}\text { HisTIOCYTES } \\
\text { OF THE } \\
\text { INFILTRATE } \\
\text { (P VALUE) }\end{array}$} & \multirow{2}{*}{$\begin{array}{l}\text { KUPFFER CELLS } \\
\text { (P VALUE) }\end{array}$} & \multirow{2}{*}{$\begin{array}{c}\text { HiSTIOCYTES } \\
\text { SURROUNDING } \\
\text { THE STEATOTIC } \\
\text { HEPATOCYTES (P VALUE) }\end{array}$} & \multicolumn{2}{|c|}{ TOTAL RESISTIN EXPRESSION } \\
\hline & & & & $\begin{array}{c}\text { CORRELATION } \\
\text { COEFFICIENT }\end{array}$ & (P VALUE) \\
\hline Glucose & 0.034 & NS & 0.026 & 0.227 & 0.001 \\
\hline $\mathrm{HbA1c}$ & 0.007 & NS & 0.002 & 0.281 & $<0.001$ \\
\hline Insulin & 0.001 & NS & 0.004 & 0.264 & 0.001 \\
\hline HOMA index & 0.001 & NS & $<0.001$ & 0.272 & 0.001 \\
\hline Triglycerides & 0.028 & NS & 0.002 & 0.179 & 0.009 \\
\hline Vitamin $\mathrm{B}_{12}$ & 0.021 & 0.021 & NS & & NS $(p=0.054)$ \\
\hline Albumin & NS & 0.029 & NS & & NS \\
\hline AST & NS & NS & 0.021 & 0.188 & 0.006 \\
\hline ALT & NS & NS & 0.018 & 0.224 & 0.001 \\
\hline $\mathrm{LDH}$ & NS & NS & NS & 0.148 & 0.040 \\
\hline GGTP & NS & NS & NS & 0.142 & 0.040 \\
\hline HDL cholesterol & NS & 0.043 & NS & & NS \\
\hline BMI & NS & NS & NS & 0.170 & 0.013 \\
\hline $\begin{array}{l}\text { Control vs. study } \\
\text { group }\end{array}$ & NS & 0.018 & 0.002 & & 0.002 \\
\hline Dyslipidemia & NS & NS & $\mathrm{NS}(\mathrm{p}=0.055)$ & & 0.022 \\
\hline Diabetes & 0.036 & NS & $\mathrm{NS}(\mathrm{p}=0.059)$ & & 0.026 \\
\hline
\end{tabular}


statistical significance was not reached (in the case of: TC/HDL $\mathrm{p}=0.065$, creatinine $\mathrm{p}=0.059, \mathrm{C}$-peptide $\mathrm{p}=0.082$, and vitamin $\left.\mathrm{B}_{12} \mathrm{p}=0.054\right)$.

Statistically significant correlation was not observed with patient's age. No difference in resistin expression was demonstrated with sex, hypertension, or metformin treatment. A statistically significant correlation was noted with BMI. A statistically significant difference in resistin expression was observed with diabetes mellitus and dyslipidaemia, and between the control group and the study group (Table III).

\section{Discussion}

The study is focused on diseases of high epidemiological importance (NAFLD, obesity). Adipokines have been the subject of great interest recently, but the results of published studies have been contradictory. There are various observations even regarding resistin location. Like only a few others $[4,5,6,7]$, our study is unique because resistin expression was examined directly in the liver. In our study, we confirm that hepatocytes are not the source of resistin in the liver. Shen et al. [4] showed that the immunoreactivity for resistin was primarily located in perisinusoidal cells of the liver lobules, rarely in periportal space, and more marked in inflammatory spaces. Others [6] also point to Kupffer cells and hepatic stellate cells as the main place of resistin expression. Szalowska et al. [7] indicated that besides Kupffer cells, endothelium cells and rarely fibroblasts are also the place of resistin expression. In our observation, resistin expression was not limited to perisinusoidal location (in Kupffer cells), but it was distinct in the macrophages in other parts of liver lobules. This observation indicates that immune system cells are the main source of liver resistin. Additionally, we observed marked expression of resistin in histiocytes (CD68+) surrounding the steatotic hepatocytes (the more steatosis, the more marked resistin expression). It may suggest the induction of resistin secretion by lipids in hepatocytes or, conversely, the induction of hepatocyte steatosis by resistin - constitute the "first hit" in NASH development theory.

The results of most studies show higher resistin level in the serum of patients with liver steatosis vs. non-obese controls $[8,9,10]$. Higher levels of resistin in patients with NAFLD and a positive correlation with inflammation were reported in several studies $[8,11]$. However, in other studies the correlation between resistin and NAFLD was not reported $[12,13$, 14 ], or even a negative correlation was found [15]. These studies were based on serum level of resistin. There are a limited number of studies evaluating resistin expression directly in the liver. Shen et al. [4] compared patients with NAFLD (simple steatosis and NASH) vs. control group. In that study, the serum resistin level was examined (ELISA test) as well as resistin mRNA and immunohistochemistry in the liver. The serum resistin level was higher in patients with NAFLD, but there was no difference between simple steatosis and NASH. Resistin expression in the liver correlated with NAFLD stage (inflammation, hepatocyte ballooning, fibrosis). Similar results were reported by Huang et al. [6]. The authors suggest that serum resistin level reflects the whole-body fat stores, and resistin is accumulated in the liver and may play a role in aggravation of the inflammatory process. However, diverse results from different studies based on the serum level of resistin also suggest that the main source of resistin is not adipose tissue (or macrophages from adipose tissue) but the liver. We confirm a strong correlation between liver resistin expression in each analysed location and NAFLD (steatosis, hepatocytes ballooning, inflammation) with the exception of fibrosis.

Resistin is regarded as a proinflammatory cytokine. Despite a positive correlation with NAFLD stage, we found no correlation with non-specific markers of inflammation such as CRP, leucocytosis, or any white blood cells. There are studies with similar observations as ours $[8,16]$; in some of them, CRP was a weak predictive factor for NAFLD [17]. Elevated AST and ALT levels are often the indicator of liver injury. We observed a correlation between resistin levels and these parameters; additionally, we also found a correlation between total resistin expression and LDH and GGTP. However, the de Ritis index was not significant. And again, the results from the literature (usually available only for ALT) are confusing, ranging from similar in NAFLD patients [18], through no correlation at all [19], to negative correlation in obese children [20].

Resistin is a cytokine that is frequently mentioned as a potential pathogenic factor for insulin resistance, secondary to obesity. This relationship was reported in several studies on animal models (mouse or rat) $[3$, $21,22,23,24,26]$. In humans, however, the results are diverse. In healthy subjects with elevated resistin levels, a higher risk of type 2 diabetes mellitus was noted, especially in subjects with concomitant obesity or inflammatory process [27]. In a group of patients with type 2 diabetes mellitus, Kaplon-Cieslicka et al. [28] did not show a correlation between serum resistin level and BMI or HOMA index, regardless of the patient's sex. Pagano et al. [8] did not find a difference between serum resistin level and insulin resistance in NAFLD group. A decrease in resistin level was reported after bariatric surgery in a few studies [29, 30, 31, 32], usually based on serum level. In a study Moschen by et al. [29] this decrease in serum resistin levels was seen 12 months after the surgery (while six months after the surgery an increase in serum resistin levels was recorded). Moschen et al. also examined resistin levels directly in the liver, and in 
this location the decrease was seen earlier - after 6 months. In their prospective study of obese patients with NAFLD and a healthy control group, Shen et al. [4] reported a correlation between resistin expression (serum and liver) and obesity but not insulin resistance. Most studies, however, are based on serum resistin levels, and their results are confusing. A positive correlation with obesity was reported in many other studies $[6,9,33,34,35,36,37,38,39]$, but still in many others no such correlation was found $[8,13,40,41]$. Similarly, many studies show a positive correlation with insulin resistance $[9,33,34$, $35,39,41]$, while others report conflicting observations $[8,10,11,13,36,37,40]$. In obese teenagers with initially higher level of resistin, the decrease in resistin levels was observed six months after changing bad habits [6]. Our results additionally support the claim that there is a link between resistin and glucose metabolism. In most locations (especially for total resistin expression), there was a correlation with glucose, $\mathrm{HbA}_{1 \mathrm{c}}$, insulin, and HOMA index. Only in Kupffer cells was there no correlation with insulin resistance. Generally, when analysing the results of our study, we had an impression that this location was the most constant and changeless of all parts of the liver resistin expression. In most studies comparing obese patients with non-obese controls, a significant difference was found. However, when a comparison was made inside the obese group, most authors did not report correlation with BMI. We think that the statistically significant correlation with BMI inside the obese group (for total resistin expression) in our study results from the size of our group. The observation of patients following bariatric surgery $[29,30,31,32]$, where all studies report the decrease in resistin level after one year, also supports our results. Obviously, currently it is not possible to verify whether resistin can be responsible for weight gain, or whether it is only its consequence. We assume that there must be a connection with hepatic insulin resistance. Perhaps, the liver is the target organ for resistin. HOMA is one of the most commonly applied indices of insulin resistance; however, it is an index of peripheral and hepatic insulin resistance. In a study by Bajaj et al. [10] serum resistin level correlated with fat accumulation in the liver and hepatic insulin resistance (not peripheral) in patients with type 2 diabetes mellitus. An additional observation made during our study is the analysis of the diabetic group, revealing that there was no difference with metformin intake. We did not find any similar analysis in the literature. A positive role of metformin in NAFLD treatment has been postulated, but (if so) it is not a process involving resistin.

Other pathologies, probably related to resistin, are disturbances in the lipid metabolism. The results of our study generally support this theory. We noted a re- lationship between liver resistin expression and serum triglycerides level and dyslipidaemia (with the exception of Kupffer cells). In Kupffer cells, higher resistin expression was observed at lower HDL-C levels. These observations can also be attributed to insulin resistance - when insulin resistance increases, HDL levels decrease and triglyceride levels rise. Several population studies showed that cholesterol level (total and all fractions) was lower at higher resistin concentration (in obese, NAFLD, and diabetic patients) [39, 42]. Similar findings were reported in studies on rats, where excessive resistin expression led to a decrease in total cholesterol and HDL-C [43]. The authors supposed that this effect could be related to the accumulation and sequestration of cholesterol in macrophages. However, also in lipid metabolism, the results of other studies are conflicting, showing no correlation or a positive correlation with total cholesterol and a negative correlation with HDL-C [44, 45, 46, 47, 48].

Although some studies suggest a role of iron in liver fibrosis and insulin resistance, we found no correlation with the parameters related to iron metabolism - Hgb, MCV, Fe, TIBC, transferrin, or ferritin. No such studies have been reported in the literature.

Vitamin $\mathrm{B}_{12}$ is responsible for DNA methylation and plays different roles in humans. Among metformin-treated patients with type 2 diabetes mellitus, a decrease in vitamin $B_{12}$ level was observed [ 49 , 50]. In patients with low vitamin $B_{12}$ level, unfavourable changes in lipids also take place, with an increase in total cholesterol and LDL-C and a decrease in HDL-C [49]. In one of study [51] the authors suggest a potential protective role of vitamin $B_{12}$ - in rats fed with NDMA (N-nitrosodimethylamine), vitamin $\mathrm{B}_{12}$ improved liver parameters. In our study there was a correlation between serum vitamin $B_{12}$ level and resistin expression in macrophages and Kupffer cells (statistically significant). No such analyses are available in the literature.

In conclusion, we presume that resistin aggravates pathologic changes in the liver of patients with NAFLD. We also confirm that resistin plays a role in the pathogenesis of hepatic insulin resistance. There are still many question marks regarding the role of resistin and its metabolism. We believe that the results of our study will be of value for further analyses since the group of our patients is one of the largest reported in literature.

The authors declare no conflict of interest.

\section{References}

1. Orlik B, Handzlik G, Olszanecka-Glinianowicz M. The role of adipokines and insulin resistance in the pathogenesis of nonalcoholic fatty liver disease. Postepy Hig Med Dosw 2010; 64: 212-219. 
2. Musso G, Gambino R, Cassader M, et al. Meta-analysis: natural history of non-alcoholic fatty liver disease (NAFLD) and diagnostic accuracy of non-invasive tests for liver disease severity. Ann Med 2011; 43: 617-649.

3. Banerjee RR, Rangwala SM, Shapiro JS, et al. Regulation of fasted blood glucose by resistin. Science 2004; 303: 1195-1198.

4. Shen C, Zhao CY, Wang W, et al. The relationship between hepatic resistin overexpression and inflammation in patients with nonalcoholic steatohepatitis. BMC Gastroenterol 2014; 23: $14-39$

5. Kleiner DE, Brunt EM, Van Natta M, et al. Design and validation of a histological scoring system for nonalcoholic fatty liver disease. Hepatology 2005; 41: 1313-1321.

6. Huang F, Del-Rio-Navarro BE, Pérez-Ontiveros JA, et al. Effect of six-month lifestyle intervention on adiponectin, resistin and soluble tumor necrosis factor- $\alpha$ receptors in obese adolescents. Endocr J 2014; 61: 921-931.

7. Szalowska E, Elferink MG, Hoek A, et al. Resistin is more abundant in liver than adipose tissue and is not up-regulated by lipopolysaccharide. J Clin Endocrinol Metab 2009; 94: 3051-3057

8. Pagano C, Soardo G, Pilon C, et al. Increased serum resistin in nonalcoholic fatty liver disease is related to liver disease severity and not to insulin resistance. J Clin Endocrinol Metab 2006; 91: 1081-1086.

9. Jiang LL, Li L, Hong XF, et al. Patients with nonalcoholic fatty liver disease display increased serum resistin levels and decreased adiponectin levels. Eur J Gastroenterol Hepatol 2009; 21: 662-666.

10. Bajaj M, Suraamornkul S, Hardies LJ, et al. Plasma resistin concentration, hepatic fat content, and hepatic and peripheral insulin resistance in pioglitazone-treated type II diabetic patients. Int J Obes Relat Metab Disord 2004; 28: 63-69.

11. Stejskal D, Adamovska S, Bartek J, et al. Resistin: concentrations in persons with type 2 diabetes mellitus and in individuals with acute inflammatory disease. Biomed Pap 2003; 147: 63-69.

12. Wong VW, Hui AY, Tsang SW, et al. Metabolic and adipokine profile of Chinese patients with nonalcoholic fatty liver disease. Clin Gastroenterol Hepatol 2006; 4: 1154-1161.

13. Jarrar MH, Baranova A, Collantes R, et al. Adipokines and cytokines in non-alcoholic fatty liver disease. Aliment Pharmaco Ther 2008; 27: 412-421.

14. Krawczyk K, Szczesniak P, Kumor A, et al. Adipohormones as prognostic markers in patients with nonalcoholic steatohepatitis (NASH). J Physiol Pharmacol 2009; 60: 71-75.

15. Perseghin G, Lattuada G, De Cobelli F, et al. Serum resistin and hepatic fat content in nondiabetic individuals. J Clin Endocrinol Metab 2006, 91: 5122-5125.

16. Hui J, Farrell GC, Kench JG, et al. High sensitivity CRP protein values do not reliably predict the severity of histologic change in NAFLD. Hepatology 2004; 39: 1458-1459.

17. Park SH, Kim BI, Yun JW, et al. Insulin resistance and C-reactive protein as independent risk factors for non-alcoholic fatty liver disease in non-obese Asian Men. J Gastroenterol Hepatol 2004; 19: 694-698.

18. SenateşE, Colak Y, Yeșil A, et al. Circulating resistin is elevated in patients with non-alcoholic fatty liver disease and is associated with steatosis, portal inflammation, insulin resistance and nonalcoholic steatohepatitis scores. Minerva Med 2012; 103 : 369-376.

19. Lee YS, Cho YK, Pae JC, et al. The relationship between serum adiponectin level and serum alanine aminotransferase elevation in Korean male with nonalcoholic fatty liver disease. Korean J Hepatol 2006; 12: 221-229.

20. Boyraz M, Cekmez F, Karaoglu A, et al. Serum adiponectin, leptin, resistin and RBP4 levels in obese and metabolic syndrome children with nonalcoholic fatty liver disease. Biomark Med 2013; 7: 737-745
21. Quatanani M, Szwergold NR, Greaves DR, et al. Macrophage-derived human resistin exacerbates adipose tissue inflammation and insulin resistance in mice. J Clin Invest 2009; 119: 531-539.

22. Pravenec M, Kazdová L, Landa V, et al. Transgenic and recombinant resistin impair skeletal muscle glucose metabolism in the spontaneously hypertensive rat. J Biol Chem 2003; 278: 45209-45215.

23. Rajala MW, Obici S, Scherer PE, et al. Adipose-derived resistin and gut-derived resistin-like molecule-beta selectively impair insulin action on glucose production. J Clin Invest 2003; 111 : 225-230.

24. Rangwala SM, Rich AS, Rhoades B, et al. Abnormal glucose homeostasis due to chronic hyperresistinemia. Diabetes 2004; 53: 1937-1941.

25. Satoh H, Nguyen MT, Miles PD, et al. Adenovirus-mediated chronic "hyperresistinemia" leads to in vivo insulin resistance in normal rats. J Clin Invest 2004; 114: 224-231.

26. Steppan CM, Wang J, Whiteman EL, et al. Activation of SOCS-3 by resistin. Mol Cell Biol 2005; 25: 1569-1575.

27. Chen BH, Song Y, Ding EL, et al. Circulating levels of resistin and risk of type 2 diabetes in men and women: results from two prospective cohorts. Diabetes Care 2009; 32: 329-334.

28. Kapłon-Cieślicka A, Postuła M, Rosiak M, et al. Association of adipokines and inflammatory markers with lipid control in type 2 diabetes. Pol Arch Intern Med 2015; 125: 414-423.

29. Moschen A, Molnar C, Wolf AM, et al. Effects of weight loss induced by bariatric surgery on hepatic adipocytokine expression. J Hepatol 2009; 51: 765-777.

30. Edwards C, Hindle AK, Latham PS, et al. Resistin expression correlates with steatohepatitis in morbidly obese patients. Surg Endosc 2013; 27: 1310-1314.

31. Edwards C, Hindle AK, Fu S, et al. Downregulation of leptin and resistin expression in blood following bariatric surgery. Surg Endosc 2011; 25: 1962-1968.

32. Santoro S, Milleo FQ, Malzoni CE, et al. Enterohormonal changes after digestive adaptation: five-year results of a surgical proposal to treat obesity and associated diseases. Obes Surg 2008; 18: 17-26

33. Fujinami A, Obayashi H, Ohta K, et al. Enzyme-linked immunosorbent assay for circulating human resistin: resistin concentrations in normal subjects and patients with type 2 diabetes. Clin Chim Acta 2004; 339: 57-63.

34. Degawa-Yamauchi M, Bovenkerk JE, Juliar BE, et al. Serum resistin (FIZZ3) protein is increased in obese humans. J Clin Endocrinol Metab 2003; 88: 5452-5455.

35. Cruz-Dominguez MP, Cortés DH, Zarate A, et al. Relationship of ghrelin, acid uric and proinflammatory adipocytokines in different degrees of obesity or diabetes. Int J Clin Exp Med 2014; 7: 1435-1441

36. Vozarova de Courten B, Degawa-Yamauchi M, Considine RV, et al. High serum resistin is associated with an increase in adiposity but not a worsening of insulin resistance in Pima Indians. Diabetes 2004; 53: 1279-1284.

37. Panidis D, Koliakos G, Kourtis A, et al. Serum resistin levels in women with polycystic ovary syndrome. Fertil Steril 2004 81: 361-366

38. Silha JV, Murphy LJ. Serum resistin (FIZZ3) protein is increased in obese humans. J Clin Endocrinol Metab 2004; 89: 1977-1978.

39. Malo E, Ukkola O, Jokela M, et al. Resistin is an indicator of the metabolic syndrome according to five different definitions In the Finnish Health 2000 survey. Metab Syndr Relat Disord 2011; 9: 203-210.

40. Baranova A, Gowder SJ, Schlauch K, et al. Gene expression of leptin, resistin and adiponectin in the white adipose tissue of obese patients with non-alcoholic fatty liver disease and insulin resistance. Obes Surg 2006; 16: 1118-1125. 
41. Youn BS, Yu KY, Park HJ, et al. Plasma resistin concentrations measured by enzyme-linked immunosorbent assay using a newly developed monoclonal antibody are elevated in individuals with type 2 diabetes mellitus. J Clin Endocrinol Metab 2004; 89: 150-156

42. Cabrera de León A, Almeida González D, González Hernández A, et al. Relationship between serum resistin and fat intake, serum lipid concentrations and adiposity in the general population. J Atheroscler Thromb 2014; 21: 454-462.

43. Liu Y, Wang Q, Pan YB, et al. Effects of over-expressing resistin on glucose and lipid metabolism in mice. J Zhejiang Univ Sci 2008; 9: 44-50.

44. Al-Daghri N, Chetty R, McTernan PG, et al. Serum resistin is associated with C-reactive protein and LDL cholesterol in type 2 diabetes and coronary artery disease in a Saudi population. Cardiovasc Diabetol 2005; 5: 4-10.

45. De Luis DA, Sagrado MG, Conde R, et al. Relation of resistin levels with cardiovascular risk factors, insulin resistance and inflammation in naïve diabetes obese patients. Diabetes Res Clin Pract 2010; 89: 110-114.

46. Uslu S, Kebapçi N, Kara M, et al. Relationship between adipocytokines and cardiovascular risk factors in patients with type 2 diabetes mellitus. Exp Ther Med 2012; 4: 113-120.

47. Piestrzeniewicz K, Łuczak K, Komorowski J, et al. Resistin increases with obesity and atherosclerotic risk factors in patients with myocardial infarction. Metabolism 2008; 57: 488-493.

48. Zheng H, Xu H, Xie N, et al. Association of serum resistin with peripheral arterial disease. Pol Arch Intern Med 2013; 123: 680-685.

49. Adaikalakoteswari A, Jayashiri R, Sukumar N, et al. Vitamin B12 deficiency is associated with adverse lipid profile in Europeans and Indians with type 2 diabetes. Cardiovasc Diabetol 2014; 13: 129.

50. Niafar M, Hai F, Porhomayon J, et al. The role of metformin on vitamin B12 deficiency: a meta-analysis review. Intern Emerg Med 2015; 10: 93-102.

51. Ahmad A, Afroz N, Gupta UD, et al. Vitamin B12 supplement alleviates $\mathrm{N}$ '-nitrosodimethylamine-induced hepatic fibrosis in rats. Pharm Biol 2014; 52: 516-523.

\section{Address for correspondence}

Beata Gierej

Department of Pathology

Medical University of Warsaw

Warsaw, Poland

e-mail: beatagierej@wp.pl 